\title{
Prognostic factors affecting long-term outcomes in patients with resected stage IIIA pN2 non-small-cell lung cancer: 5-year follow-up of a phase II study
}

\author{
DC Betticher*, , S-F Hsu Schmitz, M Tötsch, E Hansen, C Joss, C von Briel, RA Schmid, M Pless, J Habicht, \\ AD Roth, A Spiliopoulos, R Stahel, W Weder, R Stupp, F Egli, M Furrer, H Honegger, M Wernli, T Cerny and \\ H-B Ris, for the Swiss Group for Clinical Cancer Research (SAKK), Bern, Switzerland \\ 'Clinic of Medical Oncology, Hospital of Fribourg, 1700 Fribourg, Switzerland, for the Swiss Group for Clinical Cancer Research (SAKK), Bern, Switzerland
}

\begin{abstract}
The aim was to investigate the efficacy of neoadjuvant docetaxel-cisplatin and identify prognostic factors for outcome in locally advanced stage IIIA (pN2 by mediastinoscopy) non-small-cell lung cancer (NSCLC) patients. In all, 75 patients (from 90 enrolled) underwent tumour resection after three 3-week cycles of docetaxel $85 \mathrm{mg} \mathrm{m}^{-2}$ (day I) plus cisplatin 40 or $50 \mathrm{mg} \mathrm{m}^{-2}$ (days I and 2). Therapy was well tolerated (overall grade 3 toxicity occurred in $48 \%$ patients; no grade 4 nonhaematological toxicity was reported), with no observed late toxicities. Median overall survival (OS) and event-free survival (EFS) times were 35 and 15 months, respectively, in the 75 patients who underwent surgery; corresponding figures for all 90 patients enrolled were 28 and 12 months. At 3 years after initiating trial therapy, 27 out of 75 patients (36\%) were alive and tumour free. At 5 -year follow-up, 60 and $65 \%$ of patients had local relapse and distant metastases, respectively. The most common sites of distant metastases were the lung (24\%) and brain (17\%). Factors associated with OS, EFS and risk of local relapse and distant metastases were complete tumour resection and chemotherapy activity (clinical response, pathologic response, mediastinal downstaging). Neoadjuvant docetaxel-cisplatin was effective and tolerable in stage IIIA pN2 NSCLC, with chemotherapy contributing significantly to outcomes.
\end{abstract}

British Journal of Cancer (2006) 94, I099-I 106. doi:I0.1038/sj.bjc.6603075 www.bjcancer.com

Published online 4 April 2006

(c) 2006 Cancer Research UK

Keywords: chemotherapy activity; downstaging; long-term survivor; stage IIIA NSCLC

Surgery remains the best standard therapy for localised lung cancer. Results from randomised studies of early stage resectable non-small-cell lung cancer (NSCLC) have shown improved survival from use of adjuvant chemotherapy (Non-small Cell Lung Cancer Collaborative Group, 1995; Arriagada et al, 2004; Strauss et al, 2004; Winton et al, 2004; Douillard et al, 2005). Improvements in 5-year survival of $12-15 \%$ have been observed with adjuvant platinum-based doublet regimens in early stage disease (stage IB-IIIA) (Strauss et al, 2004; Winton et al, 2004; Douillard et al, 2005), and adjuvant chemotherapy is now considered the standard of care after radical surgical resection. However, the associated toxicity and subjective poor tolerance of adjuvant chemotherapy are a major limitation. Patient and physician compliance is low and even in trials only $35-85 \%$ of targeted dose intensity has been achieved. Moreover, a large randomised intergroup trial failed to demonstrate any survival advantage when cisplatin and etoposide were added to postoperative radiation, compared with radiation alone for resected stage II-IIIA disease (Keller et al, 2000).

*Correspondence: Dr D Betticher; E-mail: betticherd@hopcantfr.ch Received 3 January 2006; revised 7 March 2006; accepted 7 March 2006; published online 4 April 2006
Several small randomised studies (Pass et al, 1992; Rosell et al, 1994; Roth et al, 1994) have demonstrated a benefit from neoadjuvant treatment in locally advanced disease (stage IIIA). In a large trial involving 355 patients with stage IB - IIIA NSCLC, a trend towards survival benefit was seen from neoadjuvant chemotherapy (median survival 37 months vs 26 months for surgery alone; $P=0.15$ ) (Depierre et al, 2002). Encouragingly, preoperative chemotherapy appears to be better tolerated than adjuvant chemotherapy, with a high compliance of $90-95 \%$ (Depierre et al, 2002; Betticher et al, 2003). Similarly, preliminary results of a recent randomised trial of preoperative chemotherapy (paclitaxel and carboplatin) have shown a nonsignificant trend towards improved progression-free survival and overall survival (OS) (Pisters et al, 2005).

The routine use of neoadjuvant chemotherapy in NSCLC remains controversial. Identification of predictive/prognostic factors to select patients who would derive the greatest benefit from combined modality therapy will help clarify the most appropriate clinical use of neoadjuvant chemotherapy, particularly for patients with stage IIIA disease. We report here the final and updated results of a large phase II trial in patients with $\mathrm{pN} 2$ (proven by mediastinoscopy) stage IIIA (International Union Against Cancer, UICC) disease. Analyses of potential factors associated with the development of local relapse and distant metastases are also presented. 


\section{PATIENTS AND METHODS}

\section{Patient characteristics}

Initial results of this prospective, multicentre, phase II trial of docetaxel-cisplatin induction chemotherapy have been reported previously (Betticher et al, 2003). Briefly, all patients were required to have mediastinoscopically proven, previously untreated, operable stage IIIA (T1-3 pN2 M0) NSCLC. Eligibility criteria included: age 18-75 years; World Health Organization (WHO) performance status $(P S) \leqslant 2$; forced expiratory volume $\geqslant 1.21 \mathrm{~s}^{-1}$; normal cardiac and bone marrow (leucocyte $>4.0 \times 10^{9} 1^{-1}$, platelet $>100 \times 10^{9} 1^{-1}$ ) functions and adequate hepatic (bilirubin within normal limits, aspartate aminotransferase and alanine aminotranferase $\leqslant 1.5 \times$ upper limit of normal (ULN), alkaline phosphatase $\leqslant 2.5 \times$ ULN) and kidney (creatinine clearance $>60 \mathrm{ml} \mathrm{min}^{-1}$ ) functions. The trial was approved by the local ethics committee at each participating centre, with informed, written consent obtained from all patients.

\section{Combined modality therapy}

Patients were scheduled to receive cisplatin $80 \mathrm{mg} \mathrm{m}^{-2}$ as a 1-h infusion (divided over 2 days, on days 1 and 2) plus docetaxel $85 \mathrm{mg} \mathrm{m}^{-2}$ as a 1 -h infusion on day 1 , every 3 weeks for three cycles providing haematological function was adequate (neutrophil $>1.5 \times 10^{9} 1^{-1}$, platelet $\left.>100 \times 10^{9} 1^{-1}\right)$. In view of the low toxicity observed in the first 36 patients, the protocol was subsequently amended to increase the dose of cisplatin to $100 \mathrm{mg} \mathrm{m}^{-2}$ ( $50 \mathrm{mg} \mathrm{m}^{-2}$ on days 1 and 2 ) from patient 37 onwards. Resection was performed if there was no progressive disease (PD) based on post-induction computed tomography (CT) scan and no contraindication emerging from pulmonary function testing. Postoperative mediastinal radiotherapy was to be administered to patients with positive resection margin (R1 and R2) and/or involvement of the uppermost mediastinal lymph node. A daily dose of $2 \mathrm{~Gy}$ delivered in the central axis at the mid-plane was administered 5 days/week to a cumulative dose of $60 \mathrm{~Gy}$. The irradiated field included the bronchial stump, ipsilateral hilum and vascular shadows of the mediastinum bilaterally. Postoperative chemotherapy was not administered.

\section{Evaluations}

One of the trial objectives was to identify possible prognostic factors of the combined modality treatment (chemotherapy, surgery and optional radiotherapy). We assessed the association of OS, event-free survival (EFS; an event comprising PD, relapse or death), risk of local relapse and risk of distant metastases with each of 19 potential prognostic factors: baseline patient characteristics (age, gender, PS, smoking habits, serum lactate dehydrogenase (LDH) and haemoglobin); baseline tumour characteristics (histology, tumour stage, differentiation, multilevel involvement of mediastinal lymph nodes, and nodal enlargement on CT scan); type of surgery performed (right pneumonectomy, resection margin and complete resection) and activity of chemotherapy (clinical response, pathological responses $(\geqslant 95 \%$ and $<60 \% / \geqslant 60 \%$; this cutoff represented the median amount of necrosis and fibrosis of all tumours), mediastinal downstaging, involvement of the uppermost mediastinal lymph node). Response to chemotherapy was evaluated using WHO criteria and a complete pathological response was defined as $\geqslant 95 \%$ necrosis and fibrosis. Each patient's CT scan was assessed by the respective centre's medical panel and was reviewed centrally based on the local reports. After surgery/radiotherapy, patients were seen every 3 months and investigated by CT scan until recurrence or death. The rate of relapse (local relapse or distant metastases) was recorded.
Histological diagnosis and assessment of mediastinal lymph nodes were performed using American Thoracic Society mapping criteria (Mountain and Dresler, 1997) in all patients. Histology was reviewed centrally by an experienced pneumopathologist; any discrepancies were discussed with local pathologists in order to establish a consensus on the diagnosis. Results of CT scans, mediastinoscopy and surgical procedures were also reviewed centrally, based on reports provided.

\section{Statistical analysis}

Only patients who underwent surgery after induction chemotherapy were included in the present analysis. Continuous variables were analysed by descriptive statistics and categorical variables by frequency tables. Overall survival was determined from the time of enrolment to death, while EFS was calculated as the interval between enrolment and PD, relapse, or death. Cure was defined as no relapse within 3 years. In some analyses, time to death due to tumour was calculated as OS; however, with deaths not due to tumour, patients were censored at their dates of death. Time to local relapse was similarly defined, ending at the date of documented local relapse or death due to tumour. Time to distant relapse was defined as the time between enrolment and documented metastases or tumour-related death. Time-to-event variables (e.g. OS, EFS) were estimated using the Kaplan-Meier method. Comparisons between groups were performed using the Wilcoxon rank-sum test for continuous variables, the $\chi^{2}$ or Fisher's exact test for categorical variables and the log-rank test for time-to-event variables.

The prognostic impact of certain variables on time-to-event outcomes was investigated using the Cox proportional hazards model. The association between an outcome and a potential prognostic factor was investigated separately for each individual factor (univariate analysis). The prognostic impact of mediastinal downstaging ( $\mathrm{N} 0-1 v s \mathrm{~N} 2)$, complete resection and the activity of chemotherapy on the primary tumour was also investigated in multivariate analyses including four additional established factors (age, PS, tumour stage and LDH). All $P$-values are two-sided. No correction was performed for multiple evaluations.

\section{RESULTS}

\section{Patients and treatments}

In total, 90 patients with stage IIIA pN2 NSCLC were enrolled and were assessable for toxicity and response following docetaxelcisplatin chemotherapy (Betticher et al, 2003). Chemotherapy was well tolerated and active, with $95 \%$ of the planned dose and cycles administered, and an overall response rate of $66 \%$ (including complete remissions in $8 \%$ and partial remissions in $58 \%$ of patients; PD was seen in $10 \%$ of patients) (Betticher et al, 2003).

In all, 75 patients underwent tumour resection after three cycles of chemotherapy, with positive resection margin in $16 \%$ of patients (Betticher et al, 2003). Perioperative morbidity and mortality were low (17 and 3\%, respectively). Complete pathological response was seen in $19 \%$ of resected patients. In all, 33 patients $(44 \%)$ received radiotherapy, with median total dose $60 \mathrm{~Gy}$ (range $22-70$ ). Of these, 23 patients were treated per protocol (i.e. for a positive margin and/or involvement of the upper lymph node). Nine patients who were due to receive postoperative radiotherapy did not actually receive this treatment. Owing to the small numbers of patients involved, statistical comparison between these patient groups was considered unfeasible. Table 1 summarises the characteristics of the 75 patients who underwent surgery, including the types of resection and response to chemotherapy. All results presented hereafter relate to this subset of 75 patients unless otherwise stated. 
Table I Characteristics of patients $(n=75)$, surgery and chemotherapy

\begin{tabular}{l} 
Characteristic \\
\hline Patient characteristics \\
Gender \\
Female \\
Male \\
Age (years); median \\
Performance status \\
0 \\
I \\
2
\end{tabular}

No. of patients $\%$

Number of pack-years; median (range) 45 (9-160)

$$
\begin{aligned}
& \text { Smoking habits } \\
& \text { Continued } \\
& \text { Stopped } \\
& \text { Never smoked } \\
& \text { Serum LDH }(\times \text { ULN); median (range) } \\
& >\text { I } \times \text { ULN }
\end{aligned}
$$$$
0.77(0.54-3.56)
$$$$
14
$$

$59(39-76)$

Tumour characteristics

Initial histology (pathologist from participating centres)

Squamous cell carcinoma

Adenocarcinoma

Large cell carcinoma

Poorly differentiated NSCLC

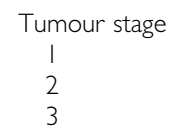

Mediastinal lymph node enlargement

$(>\mathrm{I} \mathrm{cm}$ ) by CT scan

$$
\text { Yes }
$$

No

Tumour localisation

Upper lobe right

Middle lobe right

Lower lobe right

Upper lobe left

Lower lobe left

Central right

Central left

Characteristics of the surgery

Type of resection:

Lobectomy/bilobectomy

Pneumonectomy (right/left)

Complete resection

Yes

No

Radical resection of the primary

tumour:

Negative margin

Positive margin

Activity of the chemotherapy

Response after neoadjuvant

chemotherapy

CR
PR

NC
Table I (Continued)

\begin{tabular}{lcc}
\hline Characteristic & No. of patients & $\%$ \\
\hline & & \\
Pathological response on primary & & \\
tumour (\% of necrosis and fibrosis, two & & \\
missing) & $60 \%(0-100 \%)$ & 27 \\
Median (range) & 20 & 16 \\
$\geqslant 90 \%$ & 12 & \\
$<20 \%$ & &
\end{tabular}

Downstaging of mediastinal lymph

nodes (four missing)

NO

$\mathrm{NI}$

N2

$\begin{array}{ll}23 & 32 \\ 22 & 31 \\ 26 & 37\end{array}$

$\mathrm{CT}=$ computed tomography; $\mathrm{LDH}=$ lactate dehydrogenase; NSCLC = non-smallcell lung cancer; ULN = upper limit of normal. ${ }^{a}$ Complete resection: negative resection margin (RO) and no involvement of the uppermost mediastinal lymph node in the mediastinal lymphadenectomy preparation.

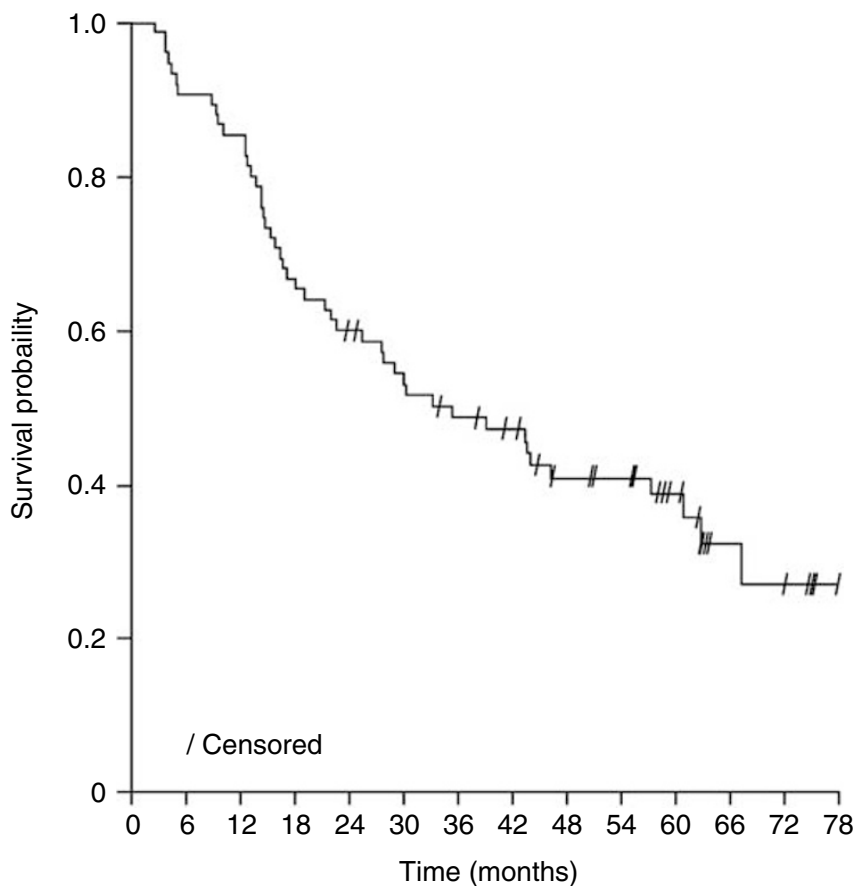

Figure I Overall survival (patients who underwent surgery, $n=75$ ).

\section{Overall survival and EFS}

After a median observation time of 5 years, the median OS was 35 months (Figure 1) and the median EFS was 15 months; corresponding survival figures for all 90 patients enrolled were 28 months and 12 months, respectively. Of 47 patients who died, 42 were due to tumour. The median time to death due to tumour was 43 months. At 3 years after initiation of trial therapy (a follow-up time which all patients reached), 27 patients (36\%) were alive and tumour free (cured). Late toxicities (dyspnoea, chest pain, myelotoxicity) due to the combined modality treatment were not seen.

\section{Prognostic factors for survival and cure}

Univariate analysis (Table 2) assessing the impact of baseline patient and tumour characteristics identified only multilevel involvement of mediastinal lymph nodes as a poor prognostic 
Table 2 Prognostic factors for overall survival, event-free survival and disease relapse (distant or local): univariate analysis

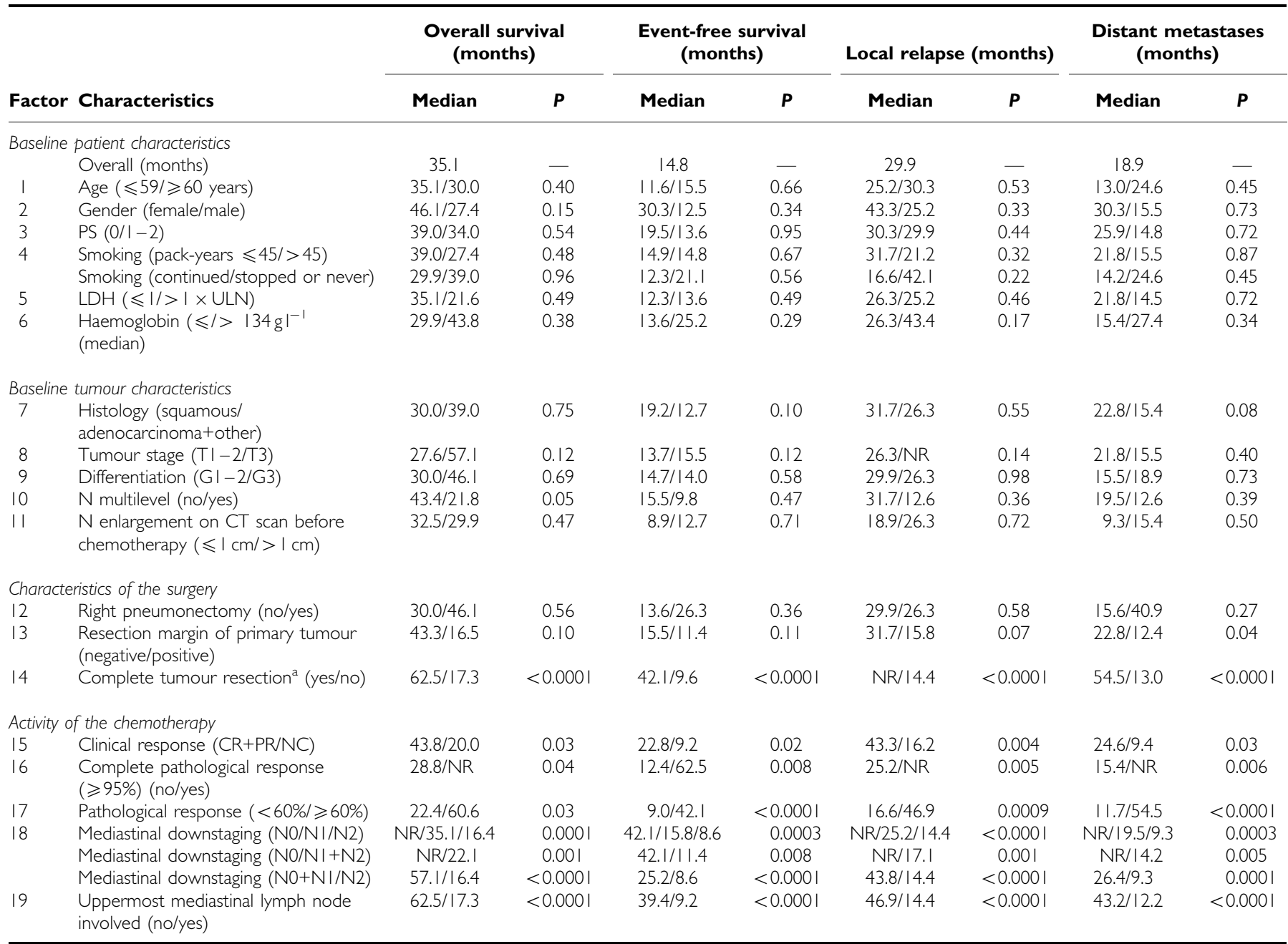

$\mathrm{CR}=$ complete response; $\mathrm{CT}=$ computed tomography; $\mathrm{LDH}=$ lactate dehydrogenase; $\mathrm{N}=$ node; $\mathrm{NC}=$ no change; $\mathrm{NR}=$ median value not reached; $P=$ log-rank test $P$-value;

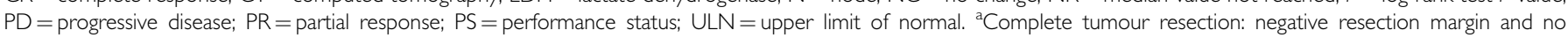
involvement of the uppermost mediastinal lymph node.

factor for OS. Among surgery characteristics, only complete resection was significantly associated with better OS and EFS. All factors relating to activity of the chemotherapy were associated with better OS and EFS. Similar associations were seen when patients who died from nontumour causes were censored (data not shown). The prognostic impacts of complete tumour resection, mediastinal downstaging and pathological response on OS and EFS were confirmed in multivariate analyses (data not shown).

In a further univariate analysis, prognostic factors for cure were identified as: clearance of the uppermost mediastinal lymph node after chemotherapy ( 23 out of 42 cures in patients with clearance $v s$ two out of 25 cures in patients without clearance; $P=0.0002$ ); $\geqslant 60 \%$ necrosis and fibrosis in the primary tumour after chemotherapy (19 out of 37 vs seven out of $33 ; P=0.01$ ); mediastinal downstaging (20 out of 43 vs four out of 25; $P=0.02$ ) and complete resection (23 out of $41 v s$ four out of 31 ; $P=0.0002$ ). Smoking habits (current or former), PS at start of therapy and age had no influence on disease evolution.

\section{Localisation of relapses}

As the first event, local relapse and distant metastases occurred in 14 out of $75(19 \%)$ and 26 out of $75(35 \%)$ patients, respectively. A further eight out of $75(11 \%)$ patients had both local relapse and distant metastases. At longer follow-up, two out of $75(3 \%)$ patients had local relapse only, six out of $75(8 \%)$ distant relapse only, 43 out of $75(57 \%)$ had both local and distant relapse, and 24 out of $75(32 \%)$ patients did not develop either relapse. In univariate analysis, the risk of local relapse and of distant metastases, including death due to tumour in both cases, was significantly associated (in terms of lower risk) with complete tumour resection and chemotherapy activity (CT-assessed clinical response, pathological response, mediastinal downstaging and clearance of the uppermost mediastinal lymph node) (Table 2). Furthermore, there were trends toward increased risk of distant metastases $(P=0.04)$ and local relapse $(P=0.07)$ in patients with a positive resection margin. The prognostic impacts of complete tumour resection, pathological response to chemotherapy and mediastinal downstaging on the risks of developing local and distant relapses were confirmed in multivariate analyses (Table 3 ).

The distribution of distant relapses is shown in Table 4. Interestingly, recurrence occurred most frequently in the lung (other lobe and/or opposite lung). In all, 10 patients (13\%) developed brain metastases as the first relapse and three (4\%) at later relapses. Of the patients, 10 developed brain metastases within 12 months of enrolment. Females (five out of $17 v s$ five out 
Table 3 Multivariate analyses for risk of developing local or distant relapse

\begin{tabular}{|c|c|c|c|c|c|c|c|c|c|c|c|c|c|}
\hline \multirow[b]{2}{*}{ Characteristic } & \multicolumn{4}{|c|}{ Univariate } & \multicolumn{3}{|c|}{ Multivariate model I } & \multicolumn{3}{|c|}{ Multivariate model 2} & \multicolumn{3}{|c|}{ Multivariate model 3} \\
\hline & $\mathbf{N}$ & $\begin{array}{l}\text { Hazard } \\
\text { ratio }\end{array}$ & $95 \% \mathrm{Cl}$ & $\mathbf{P}$ & $\begin{array}{c}\text { Hazard } \\
\text { ratio }\end{array}$ & $95 \% \mathrm{Cl}$ & $\boldsymbol{P}$ & $\begin{array}{c}\text { Hazard } \\
\text { ratio }\end{array}$ & $95 \% \mathrm{Cl}$ & $\boldsymbol{P}$ & $\begin{array}{c}\text { Hazard } \\
\text { ratio }\end{array}$ & $95 \% \mathrm{Cl}$ & $\mathbf{P}$ \\
\hline \multicolumn{14}{|c|}{ (a) Prognostic factors for time to local relapse or death due to tumour in univariate and multivariate analyses } \\
\hline Age $\geqslant 60$ & 75 & 0.83 & $0.46-1.49$ & 0.53 & 0.55 & $0.29-1.05$ & 0.07 & 0.65 & $0.35-1.22$ & 0.18 & 0.771 & $0.399-1.491$ & 0.44 \\
\hline PS $1-2$ & 75 & 0.79 & $0.43-1.45$ & 0.44 & 0.78 & $0.37-1.63$ & 0.51 & 0.95 & $0.46-1.95$ & 0.89 & 0.872 & $0.424-1.794$ & 0.71 \\
\hline Tumour stage 3 & 75 & 0.61 & $0.31-1.19$ & 0.14 & 0.76 & $0.35-1.65$ & 0.49 & 0.49 & $0.23-1.05$ & 0.06 & 0.480 & $0.220-1.047$ & 0.07 \\
\hline $\begin{array}{l}\text { Complete tumour } \\
\text { resection }\end{array}$ & 75 & 0.28 & $0.15-0.52$ & $<0.0001$ & - & - & - & 0.28 & $0.14-0.57$ & 0.0003 & - & - & - \\
\hline $\begin{array}{l}\text { Pathological } \\
\text { response } \geqslant 60 \%\end{array}$ & 73 & 0.444 & $\begin{array}{r}0.242- \\
0.813\end{array}$ & 0.0085 & - & - & - & - & - & - & 0.523 & $0.263-1.038$ & 0.06 \\
\hline \multicolumn{14}{|c|}{ (b) Prognostic factors for time to distant relapse or death due to tumour in univariate and multivariate analyses } \\
\hline $\begin{array}{l}\text { Complete tumour } \\
\text { resection }\end{array}$ & 75 & 0.32 & $0.17-0.58$ & 0.0002 & - & - & - & 0.33 & $0.18-0.64$ & 0.0009 & - & - & - \\
\hline $\begin{array}{l}\text { Pathological } \\
\text { response } \geqslant 60 \%\end{array}$ & 73 & 0.356 & $\begin{array}{r}0.199- \\
0.639\end{array}$ & 0.0005 & - & - & - & - & - & - & 0.347 & $0.181-0.663$ & 0.001 \\
\hline
\end{tabular}

$\mathrm{Cl}=$ confidence interval; $\mathrm{LDH}=$ lactate dehydrogenase; $P=$ Wald test $P$-value; $\mathrm{PS}=$ performance status; $\mathrm{ULN}=$ upper limit of normal. $\mathrm{Cl}=\mathrm{confidence}$ interval; $\mathrm{LDH}=$ lactate dehydrogenase; $P=$ Wald test $P$-value; $P S=$ performance status; $U L N=$ upper limit of normal. Although mediastinal downstaging, complete tumour resection and pathological response $(\geqslant 60 \%)$ were associated with overall survival in the univariate analyses, they also correlated with each other. It was not possible to include all of these factors in the multivariate model (this table presents the updated analysis of our previous report (Betticher et al, 2003)).

Table 4 Sites of distant metastases (at time of first diagnosis and at longer follow-up) in 75 patients. The site of metastases was documented in 37 of 49 patients, with I -3 sites per patient (total of 54 sites)

\begin{tabular}{lccc}
\hline Site & $\begin{array}{c}\text { Number of } \\
\text { patients }\end{array}$ & $\begin{array}{c}\text { \% of patients/ } \\
\text { sites }\end{array}$ & $\begin{array}{c}\mathbf{9 5 \%} \text { confidence } \\
\text { interval for } \\
\text { patients (\%) }\end{array}$ \\
\hline Lung and pleura & 18 & $24 / 33$ & $15-35$ \\
Brain & 13 & $17 / 24$ & $10-28$ \\
Lymph nodes & 7 & $9 / 13$ & $4-18$ \\
Liver & 6 & $8 / 11$ & $3-17$ \\
Skeleton & 4 & $5 / 7$ & $1-13$ \\
Skin & 3 & $4 / 6$ & $0.8-11$ \\
Adrenal glands & 2 & $3 / 4$ & $0.3-9$ \\
Peritoneal & 1 & $1 / 2$ & $0.03-7$ \\
carcinoma & & & \\
\hline
\end{tabular}

of 58 males; $P=0.04$ ) and patients with a positive resection margin (four out of $12 v s$ six out of 63 with a negative resection margin; $P=0.05)$ were at a higher risk of developing brain metastases within the first 12 months.

\section{Associations of chemotherapy activity and outcomes}

As shown in Table 2, all aspects of chemotherapy activity (clinical response, pathological response, mediastinal downstaging and clearance of the uppermost mediastinal lymph node) were significantly associated with improved OS and EFS. Pathological response (percentage of necrosis and fibrosis) was the most important feature of the chemotherapy activity on the primary tumour. The median value of pathological response was $60 \%$; this was taken as the main cutoff point to dichotomise the variable, although calculations with other cutoff points were also performed. In our study, preoperative CT scan was a relatively poor way to restage patients after neoadjuvant chemotherapy and often underestimated the degree of local tumour regression. Indeed, 20 patients with stable disease had a median of $47.5 \%$ (range $0-100 \%)$ necrosis and fibrosis and in three patients a complete $(\geqslant 95 \%)$ pathological response was found. Four patients with stable disease at resection and without any recurrence within 3 years had a median of $75 \%(30-100 \%)$ necrosis and fibrosis. Tumours of 26 patients who were relapse-free within 3 years of enrolment showed a median of $85 \%(0-100 \%)$ necrosis and fibrosis.

The risk of developing distant metastases was almost zero after 27 months if the chemotherapy induced $\geqslant 60 \%$ necrosis/fibrosis in the tumour (Figure 2A). Conversely, local relapse was seen until 4 years after enrolment, although chemotherapy was active as shown by the amount of necrosis and fibrosis in the tumour and mediastinal downstaging (Figure $2 \mathrm{~B}$ and $\mathrm{D}$ ). Importantly, for risk of distant metastases and of local relapse, the hazard ratios of the group with high pathological response $v s$ the group with low response decreased as the cutoff point increased $(P \leqslant 0.01)$. When comparing patients who achieved a complete pathological response $(\geqslant 95 \%$ necrosis and fibrosis, the largest cutoff point; $13(16 \%)$ patients) with those who did not, the hazard ratios for local relapse and for distant metastases were 0.21 and 0.26 , respectively.

\section{DISCUSSION}

The final analysis of the study data after a longer follow-up (median 5 years) confirms and strengthens our previous conclusions (Betticher et al, 2003). The median survival of the 90 patients included in the trial and for the 75 resected patients was 28 months and 35 months, respectively. To our knowledge, these are among the best results obtained in stage IIIA pN2 NSCLC patients. In a similar group of patients who had received three cycles of cisplatin 

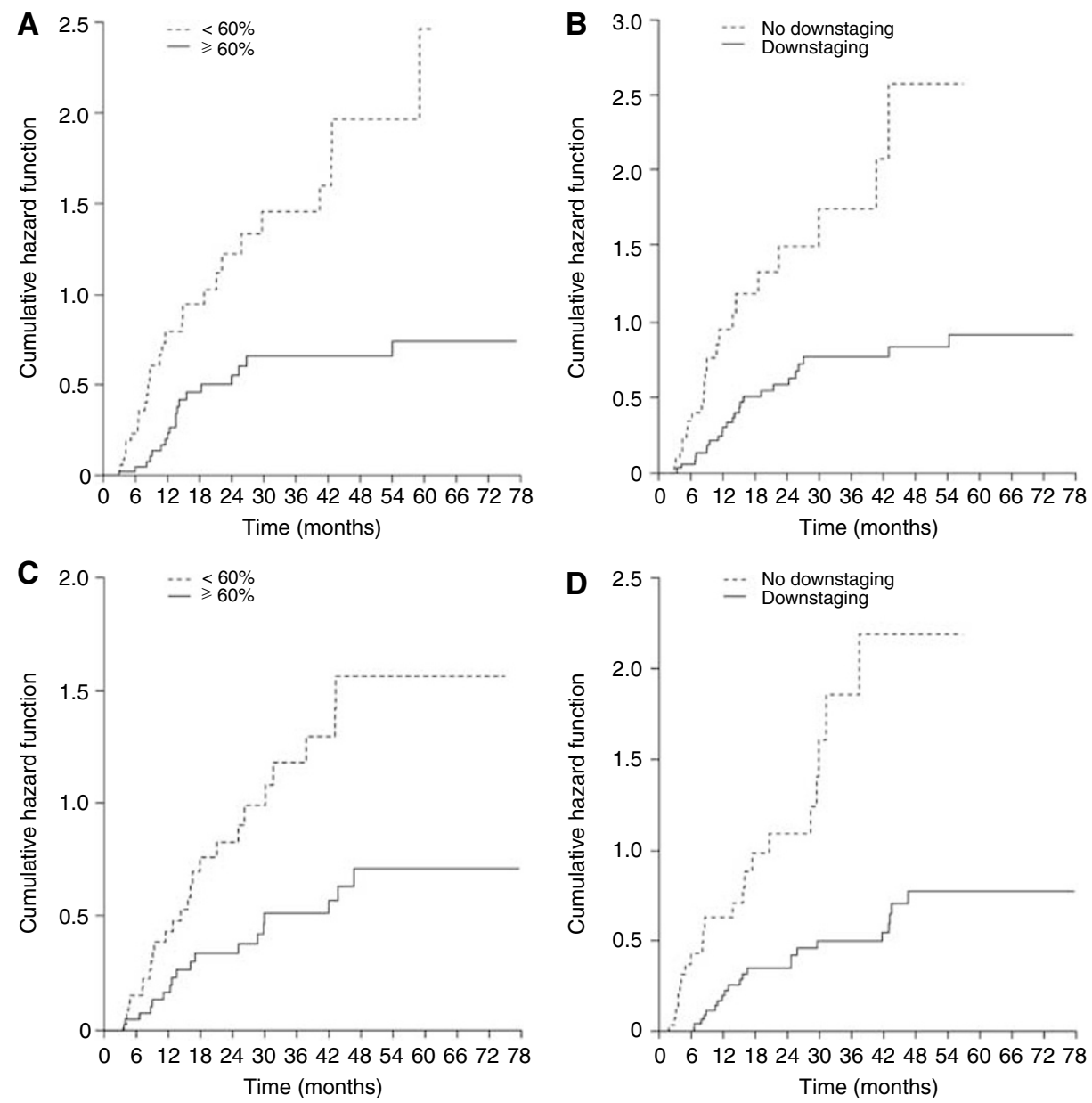

Figure 2 Risk of $(\mathbf{A})$ distant metastases stratified by pathological response (percentage of tumour necrosis and fibrosis), (B) distant metastases stratified by mediastinal downstaging (N0/I vs N2), (C) local relapse stratified by pathological response and (D) local relapse stratified by mediastinal downstaging. The risk of developing distant metastases decreased rapidly after 24 months in patients where chemotherapy was active. Conversely, local relapses occurred throughout the entire observation period.

and gemcitabine preoperatively, the median survival was 18.9 months (Van Zandwijk et al, 2000), while two other trials reported median survival times of 19 and 22 months for patients with stage IIIA pN2 NSCLC who received neoadjuvant chemotherapy (Martini et al, 1993; Rosell et al, 1999).

We sought to identify characteristics of the neoadjuvant chemotherapy, as well as other prognostic factors, which would allow enhancement of therapy and help select patients for thoracotomy. Several factors have been previously described that predict favourable long-term outcome from a multimodality approach, including clinical and pathological response to chemotherapy, the ability to completely resect the tumour and the mediastinal lymph nodes, and complete clearance of N2 disease (Albain et al, 1995; Elias et al, 1997; Burkes et al, 2005). In agreement with these results, we found that chemotherapy activity at the primary tumour, mediastinal downstaging and complete tumour resection (with a negative uppermost mediastinal lymph node) were strongly associated with improved OS and EFS, and reduced risk of local and distant relapse. Our identification of nodal downstaging from $\mathrm{N} 2$ to $\mathrm{N} 1$ and/or $\mathrm{N} 0$ as a powerful prognostic marker is consistent with findings by Albain et al (1995), who found that mediastinal nodal downstaging (to N0) was predictive of improved survival in IIIA/IIIB patients, although inclusion of preoperative radiotherapy makes it difficult to evaluate the independent effect of neoadjuvant chemotherapy on this outcome. Similarly, in a retrospective analysis of 103 patients who underwent neoadjuvant therapy and resection for stage IIIA pN2 disease, downstaging to NO was associated with improved 5 -year survival compared with patients who were N2 or N1 after chemotherapy (no difference in survival was seen between N2 and $\mathrm{N} 1$ patients in this analysis) (Bueno et al, 2000).

We demonstrated that the activity of the chemotherapy on the tumour and on lymph nodes, as characterised by the amount of necrosis and fibrosis and clearance of the malignant cells, respectively, was highly associated with outcomes. Several trials assessing the role of neoadjuvant chemotherapy, as compared to local treatment (surgery or radiotherapy), demonstrated a reduction of the risk of distant metastases (Le Chevalier et al, 1991; Sause et al, 1995; Dillman et al, 1996; Depierre et al, 2002). To our knowledge, our data show for the first time that the risk of local relapse can be reduced in relation to the extent of chemotherapy activity on the primary tumour. In fact, in patients with $\geqslant 60 \%$ pathological response, the risk of local relapse and distant metastases was reduced by 56 and $64 \%$, respectively. In patients with a lesser response, local relapse was frequent ( $60 \%$ of patients) and occurred up to 4 years after enrolment. Conversely, most cases of distant metastases were seen within 2 years following enrolment, after which the risk decreased almost to zero. Therefore, our efforts should also be concentrated on further reducing the risk of local relapse alongside reduction of distant metastases.

In our study, the most frequent site of distant metastases was the lung. This contrasts with the results reported by others who 
described the brain as the most common site of recurrence (Burkes et al, 1992, 2005; Albain et al, 1995; Darwish et al, 1995; Choi et al, 1997; Eberhardt et al, 1998; Mamon et al, 2005). Approximately, $40 \%$ of patients with stage IIIA NSCLC treated with preoperative chemotherapy and surgical resection have been reported to develop brain metastases (Andre et al, 2001; Mamon et al, 2005). The risk of developing brain metastases appears to be associated with nonsquamous histology (Robnett et al, 2001; Mamon et al, 2005) and with the type of chemotherapy. Indeed, in one retrospective analysis, treatment with a taxane - platinumcontaining regimen was associated with a lower risk of brain metastases than other platinum-based combinations (25 vs 52\%, respectively) (Mamon et al, 2005). Unexpectedly, in our study we found a lower incidence of brain metastases: $13 \%$ as first relapse site and $3 \%$ at later relapse ( $17 \%$ in total); 10 of 13 relapses occurred within the first 12 months. Female subjects seemed to be at a higher risk of developing brain metastases. The low number of cases, however, does not allow further conclusions. The role of prophylactic cranial irradiation needs to be carefully investigated and weighed against late toxicity in patients receiving neoadjuvant docetaxel and cisplatin, as this regimen apparently may reduce the risk of the development of brain metastases.

Analysis of resected tissue after chemotherapy identified a group of patients already destined for long-term survival due to tumour eradication by induction therapy. In these cases, surgical resection perhaps acted more as a diagnostic and prognostic tool to select patients for complete resection rather than providing therapeutic benefit. However, the persistence of malignant cells in the uppermost mediastinal lymph node following chemotherapy was associated with a higher risk of local relapse and development of distant metastases. Moreover, patients without any relapse within 3 years had tumours with a median of $15 \%$ viable cells. These findings suggest that further therapy is crucial for long-term survival, even in patients who respond to induction chemotherapy; however, it is not clear whether surgery is the best means to achieve this. Results from a phase III trial comparing chemotherapy and radiotherapy with preoperative chemotherapy and surgical resection in patients with stage IIIA pN2 NSCLC found no survival differences between treatment arms (Johnstone et al, 2002). In contrast, the final results from a study conducted by the North American Intergroup, in which patients with stage IIIA NSCLC were randomised to postinduction resection or further

\section{REFERENCES}

Albain KS, Rusch VW, Crowley JJ, Rice TW, Turrisi III AT, Weick JK, Lonchyna VA, Presant CA, McKenna RJ, Gandara DR (1995) Concurrent cisplatin/etoposide plus chest radiotherapy followed by surgery for stages IIIA (N2) and IIIB non-small-cell lung cancer: mature results of Southwest Oncology Group phase II study 8805. J Clin Oncol 13: $1880-1892$

Albain KS, Scott CB, Rusch VR, Turrisi AT, Shepherd SA, Smith C, Gandara DR, Johnson D, Green MR, Miller RC (2003) Phase III study of concurrent chemotherapy and full course radiotherapy (CR/RT) versus $\mathrm{CT} / \mathrm{RT}$ induction followed by surgical resection for stage IIIA(pN2) nonsmall cell lung cancer (NSCLC): first outcome analysis of North American Intergroup trial 0139 (RTOG 93-09). Lung Cancer 41(Suppl 2): S4 PL-4

Albain KS, Swann RS, Rusch VR, Turrisi AT, Shepherd FA, Smith CJ, Gandara DR, Johnson DH, Green MR, Miller RC, the North American Lung Cancer Intergroup (2005) Phase III study of concurrent chemotherapy and radiotherapy (CT/RT) vs CT/RT followed by surgical resection for stage IIIA(pN2) non-small cell lung cancer (NSCLC): outcomes update of North American Intergroup 0139 (RTOG 9309). J Clin Oncol 23(Suppl 16S): 624s (Abstr 7014)

Andre F, Grunenwald D, Pujol JL, Girard P, Dujon A, Brouchet L, Brichon PY, Westeel V, Le Chevalier T (2001) Patterns of relapse of N2 nonsmallcell lung carcinoma patients treated with preoperative chemotherapy: chemotherapy and radiotherapy following induction with chemoradiotherapy, showed improved progression-free survival in the surgery arm (Albain et al, 2003, 2005). The European Organisation for Research and Treatment of Cancer (EORTC) study (INT 08941) randomised patients with nonresectable locally advanced stage IIIA disease to cisplatin-based induction chemotherapy followed either by surgery or radiotherapy. Survival was comparable with either strategy (van Meerbeeck et al, 2005).

The lack of consistent restaging after induction chemotherapy, and the difficulty in accurately assessing tumour response shortly after completing the induction treatment, limits the comparability between studies and strategies. In several studies, and most notably in the recently reported EORTC trial, patients were excluded from attempted surgical resection in the absence of a response to induction therapy. In fact, patients with 'clinically stable disease' following neoadjuvant therapy not uncommonly have major pathological response at the time of surgery, as has been observed previously (Albain et al, 1995) and in the present trial. Clearly, better methods of assessing response after preoperative therapy are needed. Positron emission tomography may be a more accurate tool for assessing tumour response and is currently being prospectively investigated in several trials.

In conclusion, our results with neoadjuvant docetaxel and cisplatin in patients with locally advanced NSCLC (stage IIIA pN2) who underwent surgical resection revealed that, after a median follow-up of 5 years, a cure rate of $36 \%$ of resected patients can be obtained; also, the activity of chemotherapy on the primary tumour and on mediastinal lymph nodes correlate with improved OS and EFS, and reduced risk of local relapse and distant metastases. In addition, we observed a high rate of local relapse, thereby encouraging the further investigation of radiotherapy in this patient group. Finally, the risk of brain metastases was lower than that reported in previous trials.

\section{ACKNOWLEDGEMENTS}

We acknowledge the support of Aventis Pharmaceuticals, part of the sanofi-aventis Group, for providing the study drug and an unrestricted grant (used towards the data management for the trial). should prophylactic cranial irradiation be reconsidered? Cancer 91: $2394-2400$

Arriagada R, Bergman B, Dunant A, Le Chevalier T, Pignon JP, Vansteenkiste J, the International Adjuvant Lung Cancer Trial Collaborative Group (2004) Cisplatin-based adjuvant chemotherapy in patients with completely resected non-small-cell lung cancer. $N$ Engl $J$ Med 350: 351-360

Betticher DC, Hsu Schmitz S-F, Tötsch M, Hansen E, Joss C, von Briel C, Schmid RA, Pless M, Habicht J, Roth AD, Spiliopoulos A, Stahel R, Weder W, Stupp R, Egli F, Furrer M, Honegger H, Wernli M, Cerny T, Ris HB (2003) Mediastinal lymph node clearance after docetaxelcisplatin neoadjuvant chemotherapy is prognostic of survival in patients with stage IIIA pN2 non-small-cell lung cancer: a multicenter phase II trial. J Clin Oncol 21: $1752-1759$

Bueno R, Richards WG, Swanson SJ, Jaklitsch MT, Lukanich JM, Mentzer SJ, Sugarbaker DJ (2000) Nodal stage after induction therapy for stage IIIA lung cancer determines patient survival. Ann Thorac Surg 70: $1826-1831$

Burkes RL, Ginsberg RJ, Shepherd FA, Blackstein ME, Goldberg ME, Waters PF, Patterson GA, Todd T, Pearson FG, Cooper JD (1992) Induction chemotherapy with mitomycin, vindesine and cisplatin for stage III unresectable non-small-cell lung cancer: results of the Toronto Phase II Trial. J Clin Oncol 10: 580-586 
Burkes RL, Shepherd FA, Blackstein ME, Goldberg ME, Waters PF, Patterson GA, Todd T, Pearson FG, Jones D, Farooq S, McGlaughlin J, Ginsberg RJ (2005) Induction chemotherapy with mitomycin, vindesine, and cisplatin for stage IIIA (T1-3, N2) unresectable non-small-cell lung cancer: final results of the Toronto phase II trial. Lung Cancer 47: $103-109$

Choi NC, Carey RW, Daly W, Mathisen D, Wain J, Wright C, Lynch T, Grossbard M, Grillo H (1997) Potential impact on survival of improved tumour downstaging and resection rate by preoperative twice-daily radiation and concurrent chemotherapy in stage IIIA non-small-cell lung cancer. J Clin Oncol 15: $712-722$

Darwish S, Minotti V, Crino L, Rossetti R, Fiaschini P, Maranzano E, Checcaglini F, Todisco T, Giansanti M, Mercati U, Vitali R, Latini P, Tonat M (1995) A phase II trial of combined chemotherapy and surgery in stage IIIA non-small cell lung cancer. Lung Cancer 12(Suppl 1): $\mathrm{S} 71-\mathrm{S} 78$

Depierre A, Milleron B, Moro-Sibilot D, Chevret S, Quoix E, Lebeau B, Braun D, Breton JL, Lemarie E, Gouva S, Paillot N, Brechot JM, Janicot H, Lebas FX, Terrioux P, Clavier J, Foucher P, Monchatre M, Coetmeur D, Level MC, Leclerc P, Blanchon F, Rodier JM, Thiberville L, Villeneuve A, Westeel V, Chastang C, the French Thoracic Cooperative Group (2002) Preoperative chemotherapy followed by surgery compared with primary surgery in resectable stage I (except T1N0), II, and IIIa non-small-cell lung cancer. J Clin Oncol 20: $247-253$

Dillman RO, Herndon J, Seagren SL, Eaton Jr WL, Green MR (1996) Improved survival in stage III non-small-cell lung cancer: seven-year follow-up of cancer and leukemia group B (CALGB) 8433 trial. J Natl Cancer Inst 88: 1210-1215

Douillard J, Rosell R, Delena M, Legroumellec A, Torres A, Carpagnano F (2005) ANITA: Phase III adjuvant vinorelbine $(\mathrm{N})$ and cisplatin $(\mathrm{P})$ versus observation (OBS) in completely resected (stage I- III) non-smallcell lung cancer (NSCLC) patients (pts): final results after 70-month median follow-up. On behalf of the Adjuvant Navelbine International Trialist Association. J Clin Oncol 23(Suppl 16S): 624s (Abstr 7013)

Eberhardt W, Wilke H, Stamatis G, Stuschke M, Harstrick A, Menker H, Krause B, Mueller MR, Stahl M, Flasshove M, Budach V, Greschuchna D, Konietzko N, Sack H, Seeber S (1998) Preoperative chemotherapy followed by concurrent chemoradiation therapy based on hyperfractionated accelerated radiotherapy and definitive surgery in locally advanced non-small-cell lung cancer: mature results of a phase II trial. J Clin Oncol 16: $622-634$

Elias A, Skarin A, Leong T, Mentzer S, Strauss G, Lynch T, Shulman L, Jacobs C, Abner A, Baldini EH, Frei III E, Sugarbaker DJ (1997) Neoadjuvant therapy for surgically staged IIIA N2 non-small cell lung. Lung Cancer 17: 147-161

Johnstone DW, Byhardt RW, Ettinger D, Scott CB (2002) Phase III study comparing chemotherapy and radiotherapy with preoperative chemotherapy and surgical resection in patients with non-small-cell lung cancer with spread to mediastinal lymph nodes (N2): final report of RTOG 89-01. Radiation Therapy Oncology Group. Int J Radiat Oncol Biol Phys 54: $365-369$

Keller SM, Adak S, Wagner H, Herskovic A, Komaki R, Brooks BJ, Perry MC, Livingston RB, Johnson DH (2000) A randomized trial of postoperative adjuvant therapy in patients with completely resected stage II or IIIA non-small-cell lung cancer. Eastern Cooperative Oncology Group. N Engl J Med 343: $1217-1222$

Le Chevalier T, Arriagada R, Quoix E, Ruffie P, Martin M, Tarayre M, Lacombe-Terrier MJ, Douillard JY, Laplanche A (1991) Radiotherapy alone versus combined chemotherapy and radiotherapy in nonresectable non-small-cell lung cancer: first analysis of a randomized trial in 353 patients. J Natl Cancer Inst 83: 417-423

Mamon HJ, Yeap BY, Janne PA, Reblando J, Shrager S, Jaklitsch MT, Mentzer S, Lukanich JM, Sugarbaker DJ, Baldini EH, Berman S, Skarin A, Bueno R (2005) High risk of brain metastases in surgically staged IIIA non-small-cell lung cancer patients treated with surgery, chemotherapy, and radiation. J Clin Oncol 23: $1530-1537$
Martini N, Kris MG, Flehinger BJ, Gralla RJ, Bains MS, Burt ME, Heelan R, McCormack PM, Pisters KM, Rigas JR (1993) Preoperative chemotherapy for stage IIIa (N2) lung cancer: the Sloan-Kettering experience with 136 patients. Ann Thorac Surg 55: 1365-1373; discussion 1373-1374

Mountain CF, Dresler CM (1997) Regional lymph node classification for lung cancer staging. Chest 111: $1718-1723$

Non-small Cell Lung Cancer Collaborative Group (1995) Chemotherapy in non-small cell lung cancer: a meta-analysis using updated data on individual patients from 52 randomised clinical trials. $\mathrm{Br}$ Med $\mathrm{J}$ 311: 899- 909

Pass HI, Pogrebniak HW, Steinberg SM, Mulshine J, Minna J (1992) Randomized trial of neoadjuvant therapy for lung cancer: interim analysis. Ann Thorac Surg 53: $992-998$

Pisters K, Vallieres E, Bunn P, Crowley J, Ginsberg R, Ellis P, Meyers B, Marks R, Treat J, Gandara D (2005) S9900: A phase III trial of surgery alone or surgery plus preoperative (preop) paclitaxel/carboplatin (PC) chemotherapy in early stage non-small cell lung cancer (NSCLC): preliminary results. J Clin Oncol 23(Suppl 16S): 624s (Abstr LBA 7012)

Robnett TJ, Machtay M, Stevenson JP, Algazy KM, Hahn SM (2001) Factors affecting the risk of brain metastases after definitive chemoradiation for locally advanced non-small-cell lung carcinoma. J Clin Oncol 19: $1344-1349$

Rosell R, Gomez-Codina J, Camps C, Javier Sanchez J, Maestre J, Padilla J, Canto A, Abad A, Roig J (1999) Preresectional chemotherapy in stage IIIA non-small-cell lung cancer: a 7-year assessment of a randomized controlled trial. Lung Cancer 26: 7-14

Rosell R, Gomez-Codina J, Camps C, Maestre J, Padille J, Canto A, Mate JL, Li S, Roig J, Olazabal A, Canela M, Ariza A, Skacel Z, Morera-Prat J, Abad A (1994) A randomized trial comparing preoperative chemotherapy plus surgery with surgery alone in patients with non-small-cell lung cancer. $N$ Engl J Med 330: $153-158$

Roth JA, Fossella F, Komaki R, Ryan MB, Putnam Jr JB, Lee JS, Dhingra H, De Caro L, Chasen M, McGavran M (1994) A randomized trial comparing perioperative chemotherapy and surgery with surgery alone in resectable stage IIIA non-small-cell lung cancer. J Natl Cancer Inst 86: $673-680$

Sause WT, Scott C, Taylor S, Johnson D, Livingston R, Komaki R, Emami B, Curran WJ, Byhardt RW, Turrisi AT (1995) Radiation Therapy Oncology Group (RTOG) 88-08 and Eastern Cooperative Oncology Group (ECOG) 4588: preliminary results of a phase III trial in regionally advanced, unresectable non-small-cell lung cancer. J Natl Cancer Inst 87: $198-205$

Strauss GM, Herndon J, Maddaus MA, Johnstone DW, Johnson EA, Watson DM, Sugarbaker DJ, Schilsky RL, Green MR (2004) Randomized clinical trial of adjuvant chemotherapy with paclitaxel and carboplatin following resection in stage IB non-small cell lung cancer (NSCLC): report of Cancer and Leukemia Group B (CALGB) Protocol 9633. J Clin Oncol 22(Suppl 14): 621s A7019

Van Meerbeeck JP, Kramer G, Van Schil PE, Legrand C, Smit EF, Schramel FM, Biesma B, Tjan-Heijnen VC, van Zandwijk N, Giaccone G, the EORTC-Lung Cancer Group (2005) A randomised trial of radical surgery (S) versus thoracic radiotherapy (TRT) in patients (pts) with stage IIIAN2 non-small cell lung cancer (NSCLC) after response to induction chemotherapy (ICT) (EORTC 08941). J Clin Oncol 23(Suppl 16S): 624s (Abstr LBA 7015)

Van Zandwijk N, Smit EF, Kramer GW, Schramel F, Gans S, Festen J, Termeer A, Schlosser NJ, Debruyne C, Curran D, Giaccone G (2000) Gemcitabine and cisplatin as induction regimen for patients with biopsyproven stage IIIA N2 non-small-cell lung cancer: a phase II study of the European Organization for Research and Treatment of Cancer Lung Cancer Cooperative Group (EORTC 08955). J Clin Oncol 18: 2658-2664

Winton TL, Livingston R, Johnson D, Rigas J, Cormier Y, Butts C, Ding K, Seymour L, Magoski N, Shepard F (2004) A prospective randomised trial of adjuvant vinorelbine (VIN) and cisplatin (CIS) in completely resected stage IB and II non small cell lung cancer (NSCLC). J Clin Oncol 22(Suppl 14): 621s A7018 